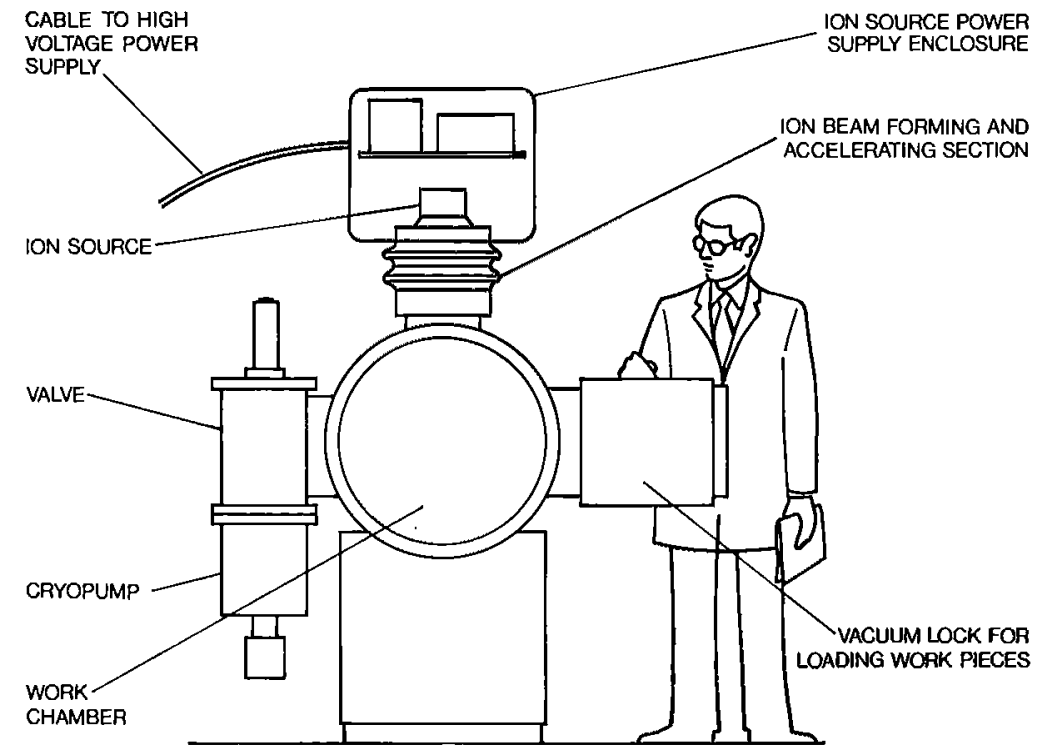

Fig. 5 Schematic diagram of an apparatus which would be suitable for testing on a laboratory scale the economic feasibility of gold ion implantation
This is not too difficult and sources exist and have been used to generate gold ions with relatively few problems because the metal is chemically inert and any alloying effects or reactive effects can be avoided by choosing appropriate materials. More recently, the liquid field emission sources of Clampitt (13) and Swanson (14) have also been used to generate gold ions. These are remarkably simple and can operate at a temperature just above the melting point of gold, say at $1100^{\circ} \mathrm{C}$. Their advantages include long, stable lifetimes and almost no demand on the vacuum system because the liquid gold is at a temperature where the vapour pressure is negligible. In addition these sources use gold with almost 100 per cent efficiency, always a consideration with an expensive material.

\section{Acknowledgements}

The author wishes to thank Andrew B. Wittkower and Walter Johnson for helpful discussion and suggestions.

\section{References}

1 E. W. Williams, Gold Bull., 1978, 11, (2), 30-34

2 G. Dearnaley, 'Defects in Crystalline Solids, Vol. 8, Ion Implantation', North Holland Publishing Co., 1973

3 J. Lindhard, $M$. Scharff and H. E. Schiott, K. Dan. Vidensk. Selsk. Mat.-Fys., 1963, 33, (14), 1-39

4 V. O. Nielson, 'Electromagnetically Enriched Isotopes and Mass Spectrometry', Academic Press, New York, 1956

5 J. F. Gibbons, W. S. Johnson and S. W. Mylroie, 'Projected Range Statistics', 2nd Edition, Halsted Press, 1975

$6 \mathrm{H}$. H. Anderson, 'Seventh Yugoslav Symposium on Physics of Ionized Gases', September 1974

7 O. Almen and G. Bruce, Nucl. Instrum. Methods, 1961, (11), 257-278

$8 \mathrm{P}$. H. Rose, in 'Proceedings of the Symposium on Electron and Ion Beam Science \& 'Technology', 1978, pp. 534-539

9 L. Valyi, 'Atom \& Ion Sources', John Wiley \& Sons, 1977

10 K. J. Hill and R. S. Nelson, Nucl. Instrum. Methods, 1965, (38), 15.18

11 'Electromagnetic Isotope Separators', edited by J. Koch, North Holland Publishing Co., 1958

12 A. N. Nesmeyanov, 'Vapour Pressure of the Elements', Academic Press, New York, 1963

13 R. Clampitt and D. K. Jefferies, Nucl. Instrum. Methods, 1978, (149), 739-742

14 L. W. Swanson, G. A. Schwind, A. E. Bell and J. E. Brady, 'Fifteenth Symposium on Electron, Ion and Photon Beam Technology', Boston, May 1979

\title{
Electroplating of Stainless Steel with Gold
}

Firm bonding of electroplated gold to stainless steel has been possible to date only by prior application of a thin nickel coating in a nickel activation bath. This often leads, however, to high susceptibility to corrosion, by way of pores, of gold-plated parts such as stainless steel watch straps. Furthermore, the process cannot be used for dental and medical products, because of the possibility of allergic or other effects of the nickel.

The Electroplating Group of Degussa has developed for the direct and firm bonding of gold deposits to stainless steel a novel method that does not have these disadvantages. It employs a special highly stable gold complex and is suitable mainly for chrome-nickel steels, molybdenumcontaining steels and nickel-based alloys. As the process has a strong activating effect, it can also be used for other passive materials that are difficult to electroplate with gold.

The bath for the new process has a $\mathrm{pH}$ value of 0.6 and is extremely stable and easy to maintain. The gold-coloured, bright coatings have a fine gold content of 99.5 per cent and a Vickers hardness of 165 . As the deposition rate is low, Degussa recommends that it should be applied only in thicknesses of approximately $0.2 \mu \mathrm{m}$ as a bonding layer and that a conventional bath with a high deposition rate should be used to build up this layer to the final thickness required. 